\title{
Phase 1b/3 Pharmacokinetics and Safety Study of Intravenous Posaconazole in Adult Asian Participants at High Risk for Invasive Fungal Infections
}

Depei $\mathrm{Wu} \cdot$ Yingchang Mi $\cdot$ Jianyu Weng $\cdot$ Junling Zhuang $\cdot$

Xiaoyan Ke $\cdot$ Chun Wang $\cdot$ Kaiyan Liu $\cdot$ Monika Martinho $\cdot$

Gregory A. Winchell $\cdot$ Yanqiao Zang $\cdot$ Lianzhe Xu

Received: August 26, 2021 / Accepted: December 1, 2021 / Published online: February 15, 2022

(C) The Author(s) 2022

\section{ABSTRACT}

Introduction: Antifungal prophylaxis in patients at high risk for invasive fungal infections (IFIs), such as those with acute myeloid leukemia or myelodysplastic syndromes, continues to be underused in Asia, despite the fact that it reduces IFI-related death and increases IFI-free survival. We characterized the pharmacokinetics (PK) and safety of the intravenous (IV) formulation of posaconazole in adult Asian participants at high risk for IFI.

Supplementary Information The online version contains supplementary material available at https:// doi.org/10.1007/s12325-021-02012-1.

D. $\mathrm{Wu}(\bowtie)$

Hematology Department, The First Affiliated Hospital of Soochow University, 296 Shizi Street, Cang Lang Qu, Suzhou 215006, Jiangsu, China e-mail: drwudepei@163.com

Y. Mi

Institute of Hematology and Blood Diseases Hospital, Chinese Academy of Medical Sciences and Peking Union Medical College, Tianjin 30020, China

J. Weng

Guangdong Provincial People's Hospital, Guangdong Academy of Medical Science, Guangzhou 510080, China
Methods: Participants received posaconazole IV $300 \mathrm{mg}$ twice on day 1, posaconazole IV $300 \mathrm{mg}$ once daily on days $2-10$, and posaconazole IV $300 \mathrm{mg}$ once daily or oral suspension $200 \mathrm{mg} 3$ times daily for up to 18 days for a maximum of 28 days. There were two PK sampling groups: intensive and sparse. Sparse trough PK sampling was collected from all participants on days 3, 6, $10,15,22$, and 28/end of treatment. The intensive PK group had additional sampling performed over $24 \mathrm{~h}$ on day 10. Primary end points were steady state average concentration

\section{J. Zhuang}

Peking Union Medical College Hospital, Beijing, China

\section{Ke}

Peking University Third Hospital, Beijing, China

C. Wang

Shanghai General Hospital, Shanghai, China

K. Liu

Peking University People's Hospital, Beijing, China

M. Martinho - Y. Zang - L. Xu

Merck \& Co., Inc, Kenilworth, NJ 07033, USA

G. A. Winchell

Certara USA, Inc, Princeton, NJ 08540, USA 
$\left(C_{\mathrm{avg}, \mathrm{ss}}\right)$ and percentage of participants with $C_{\text {avg,ss }} \geq 500 \mathrm{ng} / \mathrm{mL}$. Safety was assessed up to day 30/end of treatment.

Results: Seventy participants with acute myelogenous leukemia were enrolled, 30 in the intensive $\mathrm{PK}$ group and 40 in the sparse $\mathrm{PK}$ group; 57 participants completed the study, 26 in the intensive PK group and 31 in the sparse PK group. On day 10 , arithmetic mean $C_{\mathrm{avg}, \mathrm{ss}}$ was $2986 \mathrm{ng} / \mathrm{mL}$ [coefficient of variation (\%CV), $36 \%$; range, $1409-5930 \mathrm{ng} / \mathrm{mL}] ; 100 \%$ of participants in the intensive PK group $(n / N=27)$ 27) had $C_{\mathrm{avg}, \mathrm{ss}} \geq 500 \mathrm{ng} / \mathrm{mL}$. Arithmetic mean (\%CV) $C_{\min }$ was 2474 (50.4\%) and $2466 \mathrm{ng} / \mathrm{mL}$ $(42.4 \%)$ in the intensive and sparse PK groups on day 10, respectively. Safety was similar to that of previous posaconazole formulations.

Conclusion: In Asian participants at high risk for IFIs, IV posaconazole achieved the target exposure associated with efficacy that was previously established for supporting global registration of posaconazole for IV administration and was generally well tolerated.

Clinical trial registration: ClinicalTrials.gov, NCT03336502.

Keywords: Posaconazole; Pharmacokinetics; Triazole antifungal

\section{Key Summary Points}

Why carry out this study?

Antifungal prophylaxis in patients at high risk for invasive fungal infection continues to be underused in China, despite the fact that it reduces invasive fungal infection-related death and increases invasive fungal infection-free survival.

Asian patients who are immunocompromised, such as those with acute myelogenous leukemia, have a relatively high incidence of invasive fungal infections, primarily caused by Candida, Aspergillus, Cryptococcus, Mucorales, and Pneumocystis species.

To support registration of the IV posaconazole formulation in China, we characterized its pharmacokinetics and safety in Asian participants with acute myelogenous leukemia or myelodysplastic syndromes at risk for invasive fungal infections.

\section{What was learned from the study?}

The pharmacokinetic characteristics of the posaconazole IV formulation in Asian participants with hematologic malignancies are consistent with those reported in earlier studies in Western populations.

The posaconazole IV formulation provides a needed treatment option for Asian participants at risk for invasive fungal infections who are unable to tolerate oral therapy. 


\section{INTRODUCTION}

Until recently, there was little information regarding the prevalence of invasive fungal infection (IFI) in China, especially in the tropical and subtropical environments particularly suitable for fostering fungal growth [1]. Immunocompromised hosts, such as Asian patients with acute myelogenous leukemia (AML), have a relatively high incidence of IFIs, primarily caused by Candida, Aspergillus, Cryptococcus, Mucorales, and Pneumocystis species $[1,2]$. Unfortunately, antifungal prophylaxis in patients at high risk continues to be underused in Asian countries, particularly China, despite the fact that it reduces IFI-related death and increases IFI-free survival $[3,4]$.

The broad-spectrum triazole antifungal posaconazole has potent antifungal activity [2]. Posaconazole inhibits the synthesis of ergosterol, which is the primary sterol in the fungal cell membrane [2]. The oral suspension formulation of posaconazole was approved in 2013 by the China Food and Drug Administration for prophylaxis of Aspergillus and Candida infections and has been shown to provide superior protection against IFI in Asian patients with AML, acute lymphocytic leukemia, and myelodysplastic syndromes (MDS) [4-6]. A tablet formulation of posaconazole was recently approved by the China Food and Drug Administration for the same indication.

Posaconazole was initially developed as an oral suspension; its bioavailability is dependent on dosage regimen and food intake, and it is recommended that it be administered with highfat food to enhance absorption [7-9]. Time to reach maximum plasma concentration is $3-6 \mathrm{~h}$, apparent clearance $(\mathrm{CL})$ is $0.2-0.5 \mathrm{~L} / \mathrm{h} / \mathrm{kg}$, halflife is $15-35 \mathrm{~h}$, and apparent volume of distribution after oral administration is $7-25 \mathrm{~L} / \mathrm{kg}$ [7-9]. Posaconazole is metabolized primarily in the liver, and $66 \%$ of it is excreted unchanged in feces [7]. The oral suspension is dosed 3 times a day and is administered with a high-fat meal to improve bioavailability [8, 9]. Achieving and maintaining plasma posaconazole concentrations required for effective antifungal prophylaxis may be difficult in high-risk patient populations typically prescribed posaconazole oral solution, given that they may have mucositis, diarrhea, or nausea [10-12]. The tablet formulation was developed to optimize bioavailability and to improve compliance because it is taken once a day after twice-daily dosing on day 1 and its pharmacokinetics (PK) are minimally impacted by food $[13,14]$.

An intravenous (IV) formulation of posaconazole was developed to maximize the bioavailability of posaconazole in patients at high risk who may not be able to take medicine orally. A multicenter (34 sites), worldwide phase $1 \mathrm{~b} / 3$ study evaluated the PK and safety of IV posaconazole when given as antifungal prophylaxis to participants at high risk for IFI $[15,16]$. To support registration of the IV formulation in China, we characterized the PK and safety profile of the IV formulation of posaconazole in Asian participants with AML or MDS at risk for IFI.

\section{METHODS}

\section{Study Design}

This open-label, single-arm phase $1 \mathrm{~b}$ study was conducted at seven sites in China (Merck protocol 5592-120; ClinicalTrials.gov, NCT03336502). All procedures performed in studies involving human participants were in accordance with the ethical standards of the institutional and/or national research committee, and with the 1964 Helsinki Declaration and its later amendments or comparable ethical standards. Informed consent was obtained from all individual participants included in the study. The protocol was reviewed and approved by independent ethics committees at all participating study centers (Supplemental Table 1).

Participants included Asian males and females aged $\geq 18$ to $\leq 70$ years with body mass index of $\geq 15$ to $\leq 30 \mathrm{~kg} / \mathrm{m}^{2}$ at screening. Females of childbearing potential were required to use two medically accepted forms of contraception throughout the study treatment period. Participants had a central line or a peripherally inserted central venous catheter already in place 
Table 1 Baseline characteristics

\begin{tabular}{llll}
\hline Characteristics & $\begin{array}{l}\text { Intensive PK sampling group } \\
\boldsymbol{n}=\mathbf{3 0}\end{array}$ & $\begin{array}{l}\text { Sparse PK sampling group } \\
\boldsymbol{n}=\mathbf{4 0}\end{array}$ & $\begin{array}{l}\text { Total population } \\
\boldsymbol{n}=\mathbf{7 0}\end{array}$ \\
\hline $\begin{array}{l}\text { Age, years, median (range) } \\
\text { Sex, } n \text { (\%) }\end{array}$ & $38.0(19-63)$ & $46.5(20-68)$ & $42.0(19-68)$ \\
Male & $16(53.3)$ & $20(50.0)$ & $36(51.4)$ \\
Female & $14(46.7)$ & $20(50.0)$ & $34(48.6)$ \\
Weight, kg, median (range) & $59.5(43-80)$ & $62.5(43-84)$ & $60.6(43-84)$ \\
BMI, kg/m ${ }^{2}$, median (range) & $21.5(18-30)$ & $22.9(16-30)$ & $22.6(16-30)$ \\
Disease state, $n$ (\%) & & & $70(100.0)$ \\
Acute myelogenous leukemia & $30(100.0)$ & $40(100.0)$ &
\end{tabular}

$B M I$ body mass index, $P K$ pharmacokinetics

as standard of care for underlying disease, and were anticipated to develop (within 3-5 days) or had developed severe prolonged neutropenia (absolute neutrophil count $<500$ cells $/ \mathrm{mm}^{3}$ ) after receiving intensive induction or reinduction chemotherapy as a result of a new diagnosis or a first relapse of AML or after receiving myelosuppressive induction therapy for MDS in transformation to $\mathrm{AML}$, other than chronic myelogenous leukemia in blast crisis. Participants were excluded if they had received systemic antifungal therapy within 30 days of entering the study, had a known or suspected IFI, or had received posaconazole within 10 days before study entry. Other exclusion criteria were history of type 1 hypersensitivity or idiosyncratic reactions to azoles, moderate or severe liver dysfunction (defined as aspartate aminotransferase or alanine aminotransferase levels $>3 \times$ upper limit of normal and total bilirubin levels $>2 \times$ upper limit of normal), active hepatitis, cirrhosis, hepatocellular carcinoma, or other viral hepatic disease, prolonged QTc interval (> $500 \mathrm{~ms}$ ) by electrocardiography, Eastern Cooperative Oncology Group performance status $>2$ before induction chemotherapy for underlying disease, creatinine clearance (measured or calculated) $<50 \mathrm{~mL} / \mathrm{min}$ based on the Cockcroft-Gault equation, and known or suspected Gilbert's syndrome.

\section{Treatment}

Participants received posaconazole IV $300 \mathrm{mg}$ twice on day 1 ( $12 \mathrm{~h}$ apart), posaconazole IV $300 \mathrm{mg}$ once daily on days 2-10, and posaconazole IV $300 \mathrm{mg}$ once daily or $200 \mathrm{mg}$ oral suspension 3 times daily for up to 18 days for a maximum of 28 days. For posaconazole IV administration, the dose was administered through a central line for approximately $90 \mathrm{~min}$ at the same time each day after day 1 . Posaconazole oral suspension was administered with food or immediately (within $20 \mathrm{~min}$ ) after eating under physician guidance based on local labeling. High-fat meals were recommended, if applicable, because previous studies showed that exposure to posaconazole oral suspension after a single dose was increased by approximately fourfold if it was taken with a high-fat meal rather than in a fasted state $[8,9]$.

\section{Pharmacokinetics}

There were two PK sampling groups: intensive and sparse. Participants were enrolled sequentially. The first 30 participants enrolled were allotted to the intensive PK group. The remaining 40 participants were placed in the sparse PK group. Most PK parameters were 
assessed from the plasma samples taken from the intensive PK group. The sparse PK group was included to constitute an adequate safety database for the formulation being studied, and the single PK parameter assessed $\left(C_{\text {min }}\right)$ was collected to confirm that posaconazole was at steady state. Sparse trough PK sampling was collected for all participants on days $3,6,10,15$, 22 , and 28 /end of treatment. In the intensive group, sampling was also performed over $24 \mathrm{~h}$ on day 10. The 24-h sampling time points included pre-dose, $1 \mathrm{~h}$ after start of infusion, immediately before the end of infusion, approximately $15 \mathrm{~min}$ after the end of infusion, and approximately $4,8,12$, and $24 \mathrm{~h}$ after start of infusion. Primary end points were steadystate average concentration $\left(C_{\mathrm{avg}, \mathrm{ss}}\right)$ and percentage of participants with $C_{\text {avg,ss }} \geq 500 \mathrm{ng} / \mathrm{mL}$, based on previous exposure-response analyses and the observation that $500 \mathrm{ng} / \mathrm{mL}$ is the minimal inhibitory concentration required to inhibit the growth of $90 \%$ of organisms for most clinically relevant Aspergillus species $[15,17,18]$. Plasma concentrations and actual elapsed plasma sampling times relative to the time of dose were used to determine PK parameters for each treatment in each participant. $C_{\text {avg,ss }}$ was defined as the area under the curve from time zero to $24 \mathrm{~h} \quad\left(\mathrm{AUC}_{0-24 \mathrm{~h}}\right)$ divided by the dosing interval $(24 \mathrm{~h})$, and CL was calculated as AUC divided by dose for the intensive sampling subgroup. Other PK parameters, such as maximum concentration $\left(C_{\max }\right)$, time to $C_{\max }\left(T_{\max }\right)$, and $\mathrm{AUC}_{0-24 \mathrm{~h}}$, were determined for the intensive sampling subgroup. Minimum concentration $\left(C_{\min }\right)$ was calculated for both sampling groups.

\section{Safety and Efficacy}

Safety was regularly assessed up to 30 days after the end of treatment. Clinical signs and symptoms of IFI were monitored for efficacy using possible, probable, or proven IFI criteria per European Organization for Research and Treatment of Cancer Mycoses Study Group (EORTC/ MSG) 2008 criteria [19]. Survival was assessed from day 60 to day 70 .

\section{Statistical Analysis}

PK parameters were derived using Phoenix WinNonlin Professional v.6.3 (Certara, Princeton, NJ, USA). AUC was calculated using the linear trapezoidal method for ascending concentrations and the log trapezoidal method for descending concentrations up to the last quantifiable plasma concentration ( $\mathrm{AUC}_{0-\text { last }}$ ) or up to $24 \mathrm{~h}\left(\mathrm{AUC}_{0-24 \mathrm{~h}}\right)$. Descriptive statistics were generated for population demographics and safety. The safety population included all participants who received $\geq 1$ dose of the posaconazole IV solution. The per protocol population included participants who complied with the study protocol, including exposure to treatment, availability of measurements, and absence of major protocol deviations. The PK population included all participants who met inclusion/exclusion criteria, complied with all protocol procedures, had no important protocol violations, and adhered to dosing and PK regimens through the day 10 steady-state evaluation.

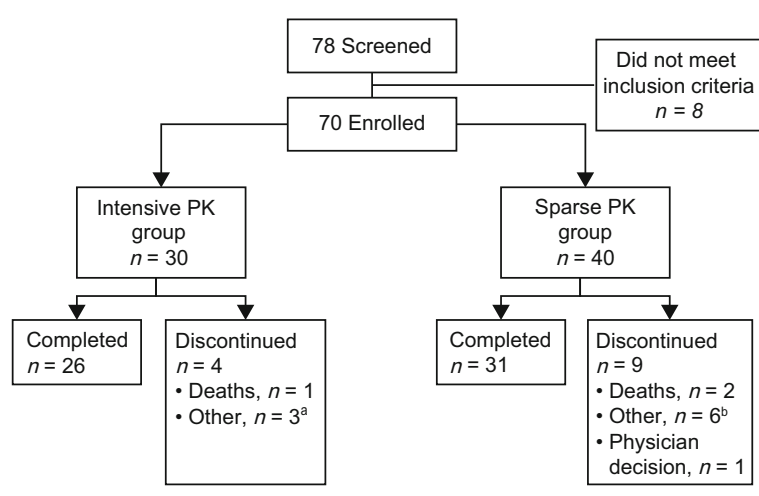

Fig. 1 Disposition of participants (all subjects as treated). ${ }^{a}$ Discontinued due to prohibited medications $(n=1)$ and adverse events (renal impairment and pyrexia; $n=1$ each). ${ }^{\mathrm{b}}$ Discontinued due to prohibited medications $(n=1)$ and adverse events (diarrhea, angina pectoris/diarrhea, embolism, ventricular tachycardia, and cardiac failure/respiratory failure; $n=1$ each). $P K$ pharmacokinetics 


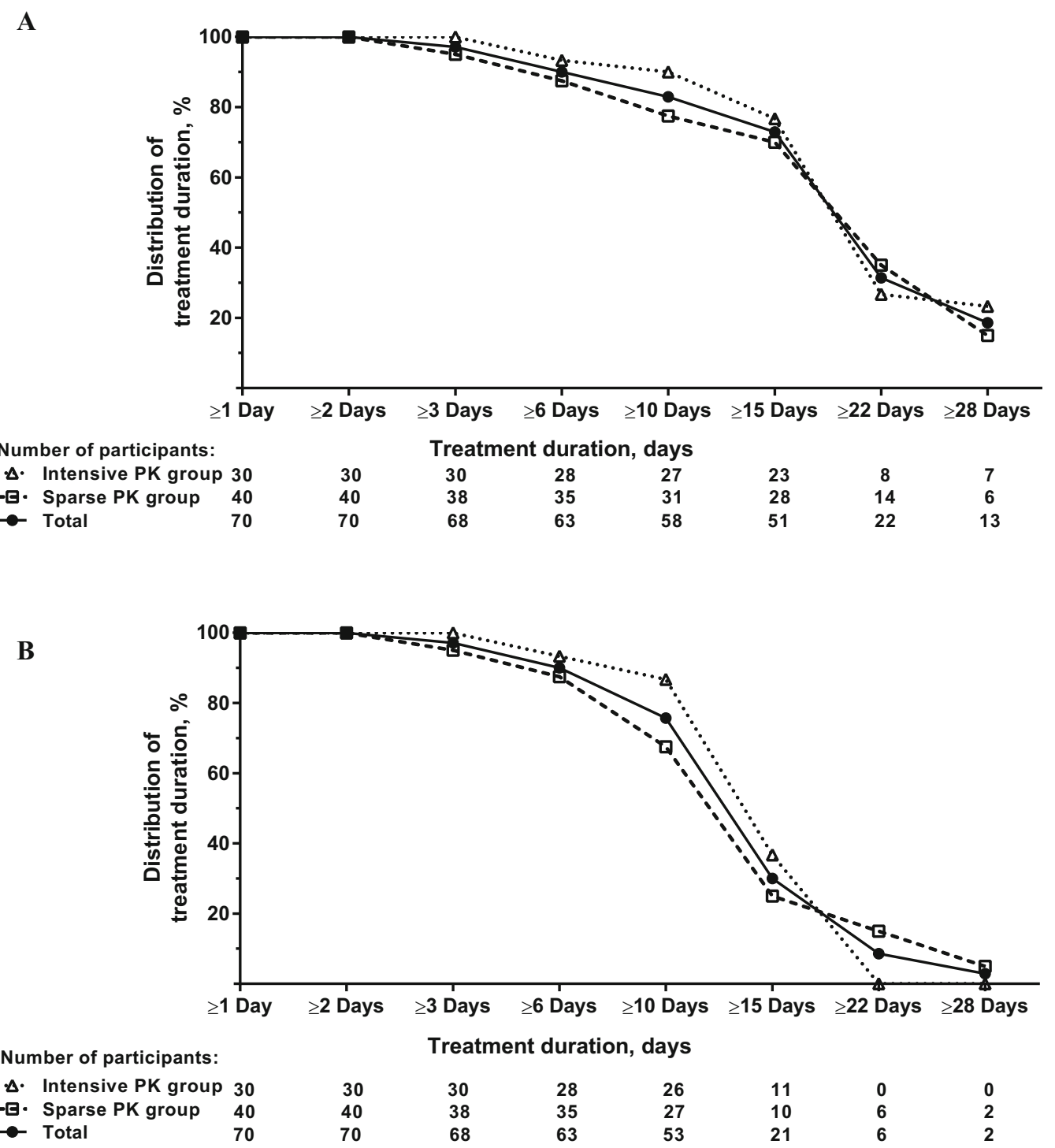

Fig. 2 Distribution of treatment duration. Interval from beginning to end of treatment (all subjects as treated). A Participants who received posaconazole IV $300 \mathrm{mg}$ plus posaconazole oral suspension $200 \mathrm{mg} 3$ times daily. B Participants who only received posaconazole IV

\section{RESULTS}

Between December 14, 2017, and November 23, 2018, 78 Asian participants were screened, of whom 8 did not meet the inclusion criteria of the study. Of the 70 enrolled in the study (36 males, 34 females), 30 were in the intensive PK sampling arm and 40 were in the sparse PK sampling arm (all subjects as treated). Fifty-
$300 \mathrm{mg}$. The number of participants is noted below the time point on the x-axis. $I V$ intravenous, $P K$ pharmacokinetics

seven participants (81.4\%) completed the study, and 13 participants (18.6\%) discontinued (Fig. 1). Among the discontinuations, three $(4.3 \%)$ were due to death, one $(1.4 \%)$ was due to physician decision, and nine (12.9\%) were due to other reasons, including adverse events (AEs; discussed in detail in the safety and efficacy section). Baseline demographic characteristics were comparable between the intensive PK 


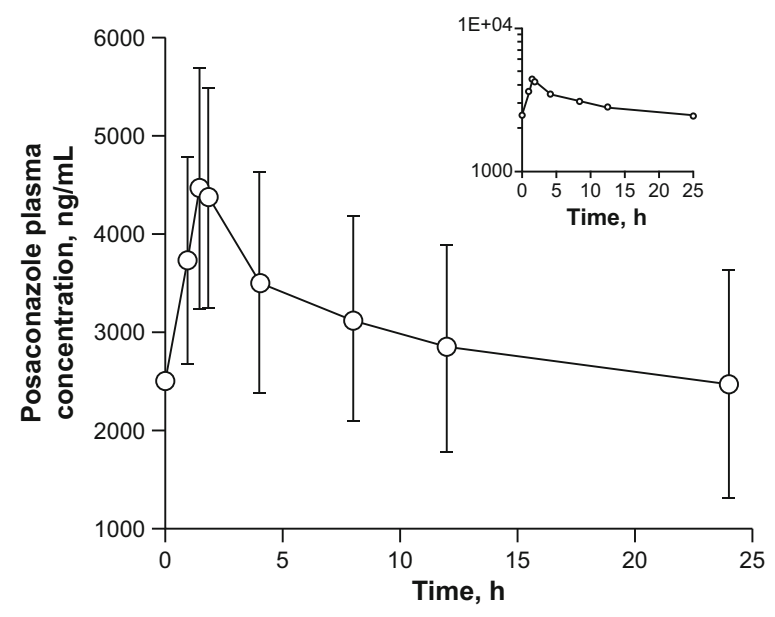

Fig. 3 Arithmetic mean $( \pm S D)$ plasma concentration $(\mathrm{ng} / \mathrm{mL})$ versus time profiles of posaconazole on day 10 in Asian participants receiving administration of posaconazole IV $300 \mathrm{mg}$ twice daily on day 1 and then posaconazole IV $300 \mathrm{mg}$ once daily until at least day 10 in the intensive PK sampling subgroup $(n=27$; inset semi-log). $I V$ intravenous, $P K$ pharmacokinetics, $S D$ stable disease

sampling and sparse PK sampling subgroups. Although participants with MDS were eligible for enrollment, all 70 participants had AML as the primary diagnosis at study entry. Detailed demographic data are presented in Table 1.

Fifty-eight participants (82.9\%) completed 10 days of posaconazole IV treatment and 13 participants $(18.6 \%)$ received 28 days of posaconazole IV solution/oral suspension treatment (Fig. 2). The mean duration of posaconazole therapy was 17.9 days. The mean duration of posaconazole IV treatment was 12.4 days.

On day 10, all 27 participants in the intensive $\mathrm{PK}$ sampling group who underwent $\geq$ 10 days of treatment had $C_{\mathrm{avg}, \mathrm{ss}} \geq 500 \mathrm{ng} / \mathrm{mL}$ : 11 of 27 participants $(40.7 \%)$ had $C_{\text {avg,ss }}$ between $500 \mathrm{ng} / \mathrm{mL}$ and $2500 \mathrm{ng} / \mathrm{mL}$, nine of 27 participants $(33.3 \%)$ had $C_{\text {avg,ss }}$ between $2500 \mathrm{ng} / \mathrm{mL}$ and $3650 \mathrm{ng} / \mathrm{mL}$, and seven of 27 participants $(25.9 \%)$ had $C_{\mathrm{avg}, \mathrm{ss}}>3650 \mathrm{ng} / \mathrm{mL}$. In the intensive PK sampling group, the arithmetic mean [coefficient of variation $(\% \mathrm{CV})$ ] of $C_{\text {avg,ss }}$ was $2986 \mathrm{ng} / \mathrm{mL}(36.0 \%)$, with $C_{\mathrm{avg}, \mathrm{ss}}$ ranging from 1409 to $5930 \mathrm{ng} / \mathrm{mL}$ (Fig. 3). Summary statistics for posaconazole PK parameters on day 10 in the intensive PK sampling subgroup are shown in Table 2.

Pre-dose $C_{\min }$ in the intensive PK and the sparse PK groups were generally comparable (Fig. 4). Based on visual inspection of the graph, steady-state appeared to be achieved before day 10 in both subgroups. All participants had $C_{\min } \geq 500 \mathrm{ng} / \mathrm{mL}$ by day 10 . On day 10 , the arithmetic mean (\%CV) and range of $C_{\min }$ were $2474 \mathrm{ng} / \mathrm{mL} \quad(50.4 \%)$ and $812-5400 \mathrm{ng} / \mathrm{mL}$, respectively, in the intensive $\mathrm{PK}$ group, and $2466 \mathrm{ng} / \mathrm{mL}$ (42.4\%) and 972-4470 $\mathrm{ng} / \mathrm{mL}$,

Table 2 Arithmetic mean (\%CV) summary of posaconazole plasma PK parameters on day 10 in Asian participants administered posaconazole IV $300 \mathrm{mg}$ twice daily on day 1 followed by posaconazole IV $300 \mathrm{mg}$ once daily until at least day 10 (all PK-evaluable participants; intensive PK sampling subgroup; $n=27$ )

\begin{tabular}{lllllll}
\hline & $\mathbf{C}_{\text {avg,ss }}(\mathbf{n g} / \mathbf{m L})$ & $\begin{array}{l}\mathbf{A U C}_{\mathbf{0}-\mathbf{2} \mathbf{h}} \\
(\mathbf{h} \times \mathbf{n g} / \mathbf{m L})\end{array}$ & $\boldsymbol{C}_{\max }(\mathbf{n g} / \mathbf{m L})$ & $\boldsymbol{C}_{\min }(\mathbf{n g} / \mathbf{m L})$ & $\boldsymbol{T}_{\max }(\mathbf{h})$ & $\mathbf{C L}(\mathbf{m L} / \mathbf{h})$ \\
\hline Mean & 2986 & 71,671 & 4612 & 2311 & 1.7 & 4768 \\
\%CV & 36.0 & 36.0 & 26.5 & 48.4 & 13.9 & 37.9 \\
Median & 3011.3 & $72,270.9$ & 4670.0 & 2150.0 & 1.7 & 4151.1 \\
Range & $1409.2-5530.4$ & $33,820.5-132,730.2$ & $2500.0-8480.0$ & $812.0-4800.0$ & $1.0-1.9$ & $2260.2-8870.4$ \\
Geometric mean & 2801.3 & $67,231.3$ & 4465.8 & 2057.1 & 1.6 & 4462.2 \\
\hline
\end{tabular}

$A U C_{0-24 h}$ area under the curve from time zero to $24 \mathrm{~h}, C_{\text {avg,ss }}$ steady state average concentration, $C L$ clearance, $C_{m a x}$ maximum concentration, $C_{\text {min }}$ minimum concentration, $I V$ intravenous, $\% C V$ coefficient of variation, $P K$ pharmacokinetics, $T_{\text {max }}$ time to maximum concentration 


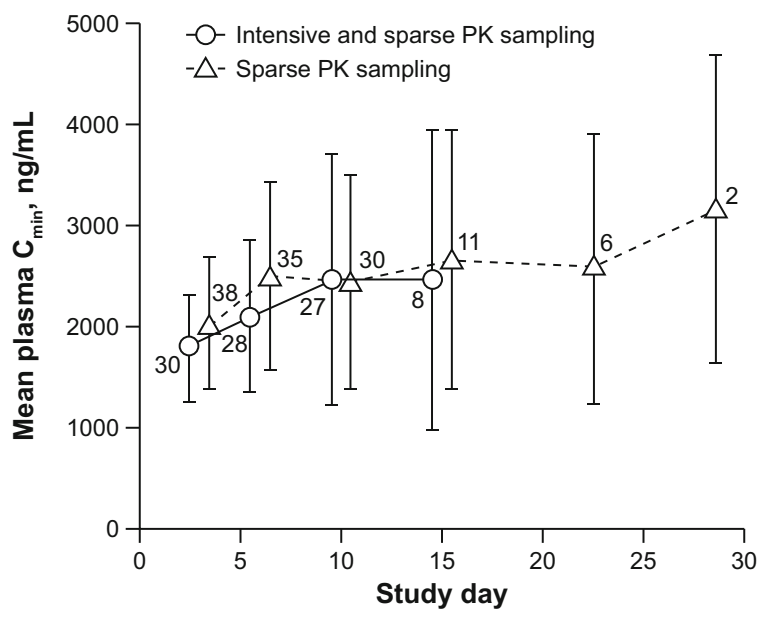

Fig. 4 Arithmetic mean $( \pm \mathrm{SD})$ plasma $C_{\text {min }}$ (pre-dose) posaconazole concentration $(\mathrm{ng} / \mathrm{mL})$ after administration of posaconazole IV $300 \mathrm{mg}$ twice daily on day 1 and then posaconazole IV $300 \mathrm{mg}$ once daily thereafter in Asian participants (all evaluable participants in the intensive PK and sparse PK sampling subgroups who received IV posaconazole throughout the study period; $n$ indicated for each point). $C_{\text {min }}$ minimum concentration, $I V$ intravenous $P K$ pharmacokinetics, $S D$ stable disease

respectively, in the sparse PK group. Variability in $C_{\min }$ after day 10 in both subgroups was high because of the much smaller sample size and must be interpreted with caution.

A comparison of posaconazole $C_{\mathrm{min}}$ in participants who remained on posaconazole IV $300 \mathrm{mg}$ once daily versus that for participants who switched to posaconazole $200 \mathrm{mg}$ oral suspension 3 times daily is shown in Fig. 5. Endof-treatment $C_{\mathrm{min}}$ in participants who remained on IV treatment overlapped, but was higher overall than in participants who switched to oral suspension.

Two participants (3\%) were classified as having a possible IFI per EORTC/MSG 2008 criteria [19] during the study period. The posaconazole $C_{\mathrm{min}}$ of each participant was $>500 \mathrm{ng} / \mathrm{mL}$ at $1210 \mathrm{ng} / \mathrm{mL}$ and $2790 \mathrm{ng} / \mathrm{mL}$. One participant was a 22-year-old male with AML (primary diagnosis). He received posaconazole IV solution from day 1 to day 19 . The result of galactomannan testing from day 2 was negative. On day 19, he was thought to have a possible IFI by computed tomography (CT), which showed bilateral pulmonary

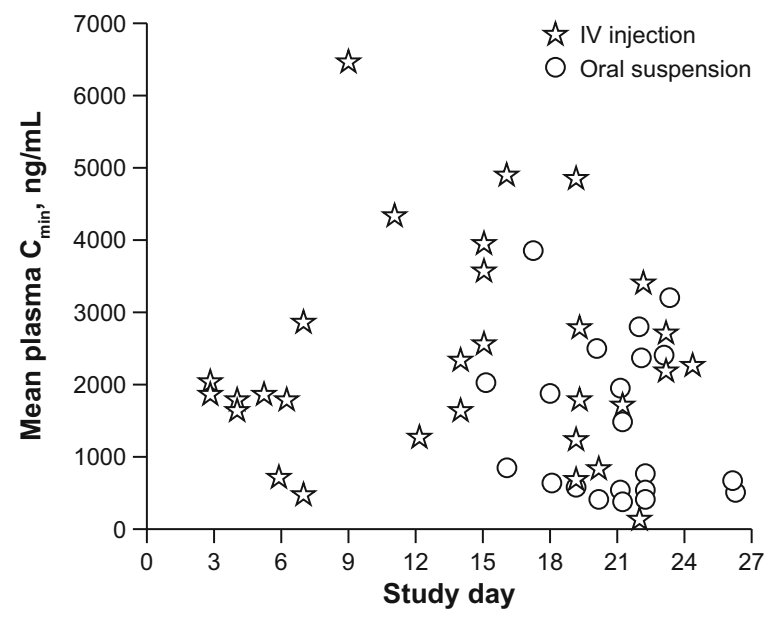

Fig. 5 Individual posaconazole plasma $C_{\min }$ (pre-dose) concentrations at the end of treatment in Asian participants after administration of posaconazole IV $300 \mathrm{mg}$ twice daily on day 1 and then posaconazole IV $300 \mathrm{mg}$ once daily, and either continued on IV administration or switched to posaconazole oral suspension $200 \mathrm{mg} 3$ times daily (all evaluable participants in the intensive PK and sparse PK sampling subgroups). $C_{\min }$ minimum concentration, $I V$ intravenous, $P K$ pharmacokinetics

infection and bilateral pleura thickened. A routine blood examination taken on day 19 showed the following: white blood cell count, $5.75 \times 10^{9} / \mathrm{L}$; hemoglobin level, $88 \mathrm{~g} / \mathrm{L}$; platelet count, $18 \times 10^{9} / \mathrm{L}$; and absolute neutrophil count, $4.17 \times 10^{9} / \mathrm{L}$. He was removed from study treatment after day 19 and received voriconazole as antifungal treatment. The second participant was a 63-year-old male with AML (primary diagnosis). He received IV posaconazole from day 1 to day 19. On day 19, he was thought to have a possible IFI by CT, which showed bilateral pulmonary infection and bilateral pleura thickened. The result of galactomannan testing from day 21 was negative. A routine blood examination showed the following: white blood cell count, $3.33 \times 10^{9} / \mathrm{L}$; hemoglobin level, $85 \mathrm{~g} / \mathrm{L}$; platelet count, $27 \times 10^{9} / \mathrm{L}$; and absolute neutrophil count, $0.78 \times 10^{9} / \mathrm{L}$. He was removed from study treatment after day 19 and was treated with antifungal therapy with voriconazole and antibacterial therapy with moxifloxacin hydrochloride. On day 23, he left the hospital with a discharge diagnosis of AML (M5b), 
Table 3 Drug-related adverse events

\begin{tabular}{|c|c|}
\hline Adverse event $n$ (\%) & Total $n=70$ \\
\hline Hypokalemia & $17(24.3)$ \\
\hline Increased blood bilirubin level & $11(15.7)$ \\
\hline Increased alanine aminotransferase level & $9(12.9)$ \\
\hline Nausea & $9(12.9)$ \\
\hline Pyrexia & $9(12.9)$ \\
\hline Vomiting & $7(10.0)$ \\
\hline Constipation & $6(8.6)$ \\
\hline Rash & $6(8.6)$ \\
\hline Diarrhea & $5(7.1)$ \\
\hline Increased aspartate aminotransferase level & $5(7.1)$ \\
\hline Hyperglycemia & $3(4.3)$ \\
\hline Hypoalbuminemia & $3(4.3)$ \\
\hline Increased weight & $3(4.3)$ \\
\hline Decreased appetite & $2(2.9)$ \\
\hline Hypocalcemia & $2(2.9)$ \\
\hline Hypophosphatemia & $2(2.9)$ \\
\hline Increased transaminases & $2(2.9)$ \\
\hline Poor quality sleep & $2(2.9)$ \\
\hline Abdominal distension & $1(1.4)$ \\
\hline Abdominal pain & $1(1.4)$ \\
\hline Abnormal hepatic function & $1(1.4)$ \\
\hline Allergic dermatitis & $1(1.4)$ \\
\hline Angina pectoris & $1(1.4)$ \\
\hline Asthenia & $1(1.4)$ \\
\hline Chest discomfort & $1(1.4)$ \\
\hline Chest pain & $1(1.4)$ \\
\hline Cough & $1(1.4)$ \\
\hline Dermatitis & $1(1.4)$ \\
\hline Dyskinesia & $1(1.4)$ \\
\hline Eye pain & $1(1.4)$ \\
\hline Hypertension & $1(1.4)$ \\
\hline Infected dermatitis & $1(1.4)$ \\
\hline
\end{tabular}

Table 3 continued

\begin{tabular}{ll}
\hline Adverse event $n$ (\%) & $\begin{array}{l}\text { Total } \\
\boldsymbol{n}=\mathbf{7 0}\end{array}$ \\
\hline Increased lacrimation & $1(1.4)$ \\
Increased brain natriuretic peptide & $1(1.4)$ \\
Increased gamma-glutamyl transferase & $1(1.4)$ \\
$\quad$ level & $1(1.4)$ \\
Oropharyngeal pain & $1(1.4)$ \\
Palpitations & $1(1.4)$ \\
Paresthesia & $1(1.4)$ \\
Peripheral edema & $1(1.4)$ \\
Photophobia & $1(1.4)$ \\
Proteinuria & $1(1.4)$ \\
Pruritus & $1(1.4)$ \\
Renal impairment & $1(1.4)$ \\
Sinus tachycardia & $1(1.4)$ \\
Sense of oppression & $1(1.4)$ \\
Upper abdominal pain & $1(1.4)$ \\
Ventricular tachycardia & $1(1.4)$ \\
Visual hallucination & \\
\hline
\end{tabular}

periproctitis, lung infection, and hypoalbuminemia. Both participants recovered, and neither was classified as having a probable or proven IFI.

All participants (100\%) experienced $\geq 1 \mathrm{AE}$, and 41 participants $(58.6 \%)$ experienced $\geq 1$ drug-related $\mathrm{AE}$ (Table 3). Common drug-related AEs (reported in $\geq 5 \%$ participants) included hypokalemia (24.3\%); increased blood bilirubin level (15.7\%); increased alanine aminotransferase level, pyrexia, and nausea (12.9\% each); vomiting (10.0\%); constipation and rash $(8.6 \%$ each); and increased aspartate aminotransferase level and diarrhea (7.1\% each). Serious AEs were reported in 15 participants (21.4\%), and only one event was judged as related to the study drug (grade 4 hypokalemia). The participant with the serious AE considered related to study drug was the 63-year- 
old male discontinued from the study because of a possible IFI.

Study drug discontinuations because of drugrelated AEs were reported for three of 70 participants $(4.3 \%)$ and consisted of one grade 1 renal impairment, one grade 1 diarrhea and 2 angina pectoris (same participant), and one grade 3 ventricular tachycardia. All drug-related AEs resolved on discontinuation of the study drug. The renal impairment occurred in a 50-year-old female with AML and no relevant medical history who received posaconazole IV solution from day 1 to day 3; study medication was permanently discontinued because of this event. The diarrhea and angina pectoris AEs occurred in a 48-year-old female with AML and a relevant medical history of chest discomfort and abdominal discomfort. The study medication was permanently discontinued because of these events, and the participant was treated with vancomycin, potassium chloride, sodium glucuronic acid, calcium gluconate, montmorillonite powder, Bifidobacterium/Lactobacillus/ Enterococcus triple probiotic, and dexamethasone. The third participant with an AE considered to be related to the study drug was a 61-year-old female with AML and a relevant medical history of hypertension who received posaconazole IV solution on days 1 and 2 and was diagnosed with grade 3 ventricular tachycardia on day 2. The study medication was permanently discontinued because of the event. The participant was treated with nifedipine, telmisartan, metoprolol, and amiodarone. All drug-related AEs resolved after posaconazole discontinuation.

Six participants died, three during study treatment and the safety follow-up period (within 30 days after the end of treatment) and three after the end of the safety follow-up period. All deaths were judged unlikely to be related to the study drug. Causes of death during study treatment and the safety follow-up period were pulmonary hypertension in a 64-year-old female with AML who received posaconazole IV on days 1-10 and posaconazole oral suspension on days 11-15, experienced a serious $\mathrm{AE}$ of pulmonary hypertension on day 15 , and died on day 16; cardiac failure in a 61-year-old male with AML who received posaconazole IV on days $1-9$, experienced a serious $\mathrm{AE}$ of cardiac failure [electrocardiography showed atrial flutter and brain natriuretic peptide level elevation at $1454 \mathrm{pg} / \mathrm{mL}$ (normal range $0-100.0 \mathrm{pg} / \mathrm{mL}$ )] on day 8 , and died on day 9; and cerebral hemorrhage in a 39-year-old female with AML who received posaconazole IV on days 1-10 and posaconazole oral solution on days 11-28 and experienced a serious $\mathrm{AE}$ of cerebral hemorrhage on day 50 and died the same day. Causes of death after the end of the safety follow-up period were acute myocardial infarction in a 58-year-old male with AML who received posaconazole IV solution on days 1-17, discontinued study treatment at the investigator's discretion on day 17 because of recovered neutrophil count $\left(2.97 \times 10^{9} / \mathrm{L}\right)$, and died of acute myocardial infarction on day 61 ; intracranial hemorrhage in a 48-year-old male with AML who received posaconazole IV solution on days 1-8, experienced serious AEs of grade 4 heart failure and grade 4 respiratory failure on day 9 , was permanently discontinued from the study drug on the same day, and died of intracranial hemorrhage on day 43; and a serious lung infection on day 2 in a 63-year-old female who received posaconazole IV solution on days 1-21 and posaconazole oral suspension on days 22-28. After completing the study treatment, she received non-study medication of posaconazole oral suspension from days 28-34 and from days 50-63. CT on day 61 indicated a fungal infection. Posaconazole oral suspension was stopped on day 63 and the participant received micafungin sodium as treatment for the fungal infection. On day 97, she died of the lung infection. Because this participant was under follow-up for the serious AE lung infection reported on day 2 , and although she died after the survival assessment on days 60-70, the death is reported here for completeness.

\section{DISCUSSION}

In this analysis of the posaconazole IV formulation in Asian participants at high risk for IFI, all evaluable study participants had $C_{\text {avg,ss }} \geq 500 \mathrm{ng} / \mathrm{mL}$. This exposure has been associated with efficacy established for 
supporting global registration of posaconazole for IV administration [15]. An IV formulation of posaconazole expands treatment options for patients with IFI who may not be able to take or absorb the medication appropriately while experiencing mucositis, diarrhea, or nausea $[12,20]$. The arithmetic $C_{\min }$ of posaconazole on day 10 in the Asian participants was $2311 \mathrm{ng} / \mathrm{mL}$, whereas it was $1297 \mathrm{ng} / \mathrm{mL}$ in 56 participants of the PK-evaluable population in the global registration study [15]. In addition, posaconazole exposures were increased by $<50 \%$ after a single IV dose of posaconazole $300 \mathrm{mg}$ in healthy Asian participants. $C_{\text {min }}$ was $4130 \mathrm{ng} / \mathrm{mL}$ in healthy Asian participants [21] compared with $2840 \mathrm{ng} / \mathrm{mL}$ in healthy Western participants [22]. Although the dose-limiting toxicity of posaconazole in humans has not been observed to date, the upper end of target exposure is usually limited to $\leq 2500 \mathrm{ng} / \mathrm{mL}$ based on previous studies of oral prophylaxis and on the therapy for refractory IFI that characterized safety for the initial approval of posaconazole oral suspension [17, 23]; the upper end of target exposure is set at $3750 \mathrm{ng} / \mathrm{mL}$ by the European Medicines Agency [24].

Safety was similar to that observed with the suspension [25], the IV formulation [15], and the oral tablet registration study in Asian participants [13]. However, the AE profile of posaconazole IV solution in Asian participants had some differences from those observed in Western populations. In particular, the incidence of liver function abnormalities appears to be higher in Asian participants compared with the Western (global) population, whereas the incidences of diarrhea, pyrexia, and nausea are lower [15]. These differences in the AE profile were also seen with the tablet formulation in Asian participants [13].

The two participants who were classified as developing possible IFIs based on EORTC/MSG criteria for classification of IFIs [19] had $C_{\text {min }}$ values $>500 \mathrm{ng} / \mathrm{mL}$ at the time of diagnosis, although these data are too limited to infer any definitive conclusions and the study was not designed to assess efficacy. IFI rates for posaconazole prophylaxis in previous studies have ranged from $2 \%$ to $3 \%[13,23,26]$.
Limitations to this study include the lack of enrollment of participants with MDS, although IV posaconazole has previously been shown to have similar PK in non-Asian participants with hematologic malignancies [15], and the limitation of enrollment to ethnic Chinese to support registration of the IV posaconazole formulation in China.

\section{CONCLUSION}

In conclusion, the PK characteristics of the posaconazole IV formulation in Asian patients with hematologic malignancies are consistent with those reported in earlier studies in Western populations, providing an efficacious and welltolerated prophylactic antifungal treatment option. The posaconazole IV formulation provides a needed treatment option for Asian patients at risk for IFI who are unable to tolerate oral therapy.

\section{ACKNOWLEDGEMENTS}

The authors thank all the study participants. They also thank Peter Schnabel (Certara USA, Inc., Princeton, NJ, USA) for assistance with non-compartmental analysis and Rebecca Ellen Wrishko (Merck \& Co., Inc., Kenilworth, NJ, USA) for assistance with pharmacokinetics.

Funding. The design, study conduct, and financial support for this research were provided by Merck Sharp \& Dohme Corp., a subsidiary of Merck \& Co., Inc., Kenilworth, NJ, USA. Merck Sharp \& Dohme Corp. also funded the journal's Rapid Service Fee.

Medical Writing Assistance. Medical writing assistance, supported by Merck Sharp \& Dohme Corp., a subsidiary of Merck \& Co., Inc., Kenilworth, NJ, USA, was provided by Jennifer M. Kulak, PhD, of ApotheCom (Yardley, PA, USA) in the preparation of this article.

Authorship. All named authors meet the International Committee of Medical Journal Editors (ICMJE) criteria for authorship for this 
article, take responsibility for the integrity of the work as a whole, and have given their approval for this version to be published.

Author Contributions. Conception and design of the study-D-PW, GAW. Acquisition of data-YM, JW, JZ, XK, CW, KL, MM. Analysis and interpretation of data-D-PW, JW, JZ, GAW, YZ, LX. Critical revision of manuscript for important intellectual content-All authors. Final approval of the version to be submittedAll authors.

Disclosures. This study was funded by Merck Sharp \& Dohme Corp., a subsidiary of Merck \& Co., Inc., Kenilworth, NJ, USA. De-Pei $\mathrm{Wu}$, Yingchang Mi, Jianyu Weng, Xiaoyan Ke, Chun Wang, and Kaiyan Liu have nothing to disclose. Junling Zhuang's institution has received money from MSD R\&D (China) Co., Ltd., for participating in clinical trial research. Gregory A. Winchell is an employee of Certara and is a subcontractor for Merck through Certara. Monika Martinho, Yanqiao Zang, and Lianzhe $\mathrm{Xu}$ are employees of Merck Sharp \& Dohme Corp., a subsidiary of Merck \& Co., Inc., Kenilworth, NJ, USA.

Compliance with Ethics Guidelines. Independent Ethics Committees reviewed and approved the protocol and applicable amendments at each study site. The main center was the Ethics committee of The First Affiliated Hospital of Soochow University. The trial was conducted in accordance with the Declaration of Helsinki, Good Clinical Practice requirements, and applicable country and/or local statutes and regulations regarding Institutional Ethics Committee review, informed consent, and protection of human participants in biomedical research.

Data Availability. The data sharing policy, including restrictions, of Merck Sharp \& Dohme Corp., a subsidiary of Merck \& Co., Inc., Kenilworth, NJ, USA is available at http:// engagezone.msd.com/ds_documentation.php. Requests for access to the clinical study data can be submitted through the Engage Zone site or via email to dataaccess@merck.com.
Open Access. This article is licensed under a Creative Commons Attribution-NonCommercial 4.0 International License, which permits any non-commercial use, sharing, adaptation, distribution and reproduction in any medium or format, as long as you give appropriate credit to the original author(s) and the source, provide a link to the Creative Commons licence, and indicate if changes were made. The images or other third party material in this article are included in the article's Creative Commons licence, unless indicated otherwise in a credit line to the material. If material is not included in the article's Creative Commons licence and your intended use is not permitted by statutory regulation or exceeds the permitted use, you will need to obtain permission directly from the copyright holder. To view a copy of this licence, visit http:// creativecommons.org/licenses/by-nc/4.0/.

\section{REFERENCES}

1. Lien MY, Chou CH, Lin CC, Bai LY, Chiu CF, Yeh $\mathrm{SP}$, et al. Epidemiology and risk factors for invasive fungal infections during induction chemotherapy for newly diagnosed acute myeloid leukemia: a retrospective cohort study. PLoS ONE. 2018;13(6): e0197851.

2. Keating GM. Posaconazole. Drugs. 2005;65(11): 1553-67.

3. Sun Y, Huang H, Chen J, Li J, Ma J, Li J, et al. Invasive fungal infection in patients receiving chemotherapy for hematological malignancy: a multicenter, prospective, observational study in China. Tumour Biol. 2015;36(2):757-67.

4. Xu XH, Zhang L, Cao XX, Li J, Zhang W, Zhu TN, et al. Evaluation of the implementation rate of primary antifungal prophylaxis and the prognosis of invasive fungal disease in acute leukemia patients in China. J Infect Chemother. 2017;23(6): 360-7.

5. Tang L, Yang XF, Qiao M, Zhang L, Tang XW, Qiu $\mathrm{HY}$, et al. Posaconazole vs voriconazole in the prevention of invasive fungal diseases in patients with haematological malignancies: a retrospective study. J Mycol Med. 2018;28(2):379-83.

6. Wang Y, Xing Y, Chen L, Meng T, Li Y, Xie J, et al. Fluconazole versus mould-active triazoles for 
primary antifungal prophylaxis in adult patients with acute lymphoblastic leukemia: clinical outcome and cost-effectiveness analysis. Int J Hematol. 2018;107(2):235-43.

7. Li Y, Theuretzbacher U, Clancy CJ, Nguyen MH, Derendorf H. Pharmacokinetic/pharmacodynamic profile of posaconazole. Clin Pharmacokinet. 2010;49(6):379-96.

8. Courtney R, Wexler D, Radwanski E, Lim J, Laughlin M. Effect of food on the relative bioavailability of two oral formulations of posaconazole in healthy adults. Br J Clin Pharmacol. 2004;57(2):218-22.

9. Krishna G, Moton A, Ma L, Medlock MM, McLeod J. The pharmacokinetics and absorption of posaconazole oral suspension under various gastric conditions in healthy volunteers. Antimicrob Agents Chemother. 2009;53(3):958-66.

10. Pille S, Bohmer D. Options for artificial nutrition of cancer patients. Strahlenther Onkol. 1998;174(Suppl 3):52-5.

11. Vehreschild MJ, Meissner AM, Cornely OA, Maschmeyer G, Neumann S, Von Lilienfeld-Toal M, et al. Clinically defined chemotherapy-associated bowel syndrome predicts severe complications and death in cancer patients. Haematologica. 2011;96(12):1855-60.

12. Sansone-Parsons A, Krishna G, Calzetta A, Wexler D, Kantesaria B, Rosenberg MA, et al. Effect of a nutritional supplement on posaconazole pharmacokinetics following oral administration to healthy volunteers. Antimicrob Agents Chemother. 2006;50(5):1881-3.

13. Liu $\mathrm{K}, \mathrm{Wu} \mathrm{D,} \mathrm{Li} \mathrm{J,} \mathrm{Chen} \mathrm{H,} \mathrm{Ning} \mathrm{H,} \mathrm{Zhao} \mathrm{T,} \mathrm{et} \mathrm{al.}$ Pharmacokinetics and safety of posaconazole tablet formulation in chinese participants at high risk for invasive fungal infection. Adv Ther. 2020;37(5): 2493-506.

14. Cornely OA, Duarte RF, Haider S, Chandrasekar P, Helfgott D, Jimenez JL, et al. Phase 3 pharmacokinetics and safety study of a posaconazole tablet formulation in patients at risk for invasive fungal disease. J Antimicrob Chemother. 2016;71(3): 718-26.

15. Cornely OA, Robertson MN, Haider S, Grigg A, Geddes M, Aoun M, et al. Pharmacokinetics and safety results from the phase 3 randomized, openlabel, study of intravenous posaconazole in patients at risk of invasive fungal disease. J Antimicrob Chemother. 2017;72(12):3406-13.

16. Maertens J, Cornely OA, Ullmann AJ, Heinz WJ, Krishna G, Patino $H$, et al. Phase $1 B$ study of the pharmacokinetics and safety of posaconazole intravenous solution in patients at risk for invasive fungal disease. Antimicrob Agents Chemother. 2014;58(7):3610-7.

17. Walsh TJ, Raad I, Patterson TF, Chandrasekar P, Donowitz GR, Graybill R, et al. Treatment of invasive aspergillosis with posaconazole in patients who are refractory to or intolerant of conventional therapy: an externally controlled trial. Clin Infect Dis. 2007;44(1):2-12.

18. Sabatelli F, Patel R, Mann PA, Mendrick CA, Norris $\mathrm{CC}$, Hare R, et al. In vitro activities of posaconazole, fluconazole, itraconazole, voriconazole, and amphotericin B against a large collection of clinically important molds and yeasts. Antimicrob Agents Chemother. 2006;50(6):2009-15.

19. de Pauw B, Walsh TJ, Donnelly JP, Stevens DA, Edwards JE, Calandra T, et al. Revised definitions of invasive fungal disease from the European Organization for Research and Treatment of Cancer/Invasive Fungal Infections Cooperative Group and the National Institute of Allergy and Infectious Diseases Mycoses Study Group (EORTC/MSG) Consensus Group. Clin Infect Dis. 2008;46:1813-21.

20. Cornely OA, Helfgott D, Langston A, Heinz W, Vehreschild JJ, Vehreschild MJ, et al. Pharmacokinetics of different dosing strategies of oral posaconazole in patients with compromised gastrointestinal function and who are at high risk for invasive fungal infection. Antimicrob Agents Chemother. 2012;56(5):2652-8.

21. Li H, Wei Y, Zhang S, Xu L, Jiang J, Qiu Y, et al. Pharmacokinetics and safety of posaconazole administered by intravenous solution and oral tablet in healthy Chinese subjects and effect of food on tablet bioavailability. Clin Drug Investig. 2019;39(11):1109-16.

22. Kersemaekers WM, van Iersel $T$, Nassander $U$, O'Mara E, Waskin H, Caceres $M$, et al. Pharmacokinetics and safety study of posaconazole intravenous solution administered peripherally to healthy subjects. Antimicrob Agents Chemother. 2015;59(2):1246-51.

23. Ullmann AJ, Lipton JH, Vesole DH, Chandrasekar P, Langston A, Tarantolo SR, et al. Posaconazole or fluconazole for prophylaxis in severe graft-versushost disease. N Engl J Med. 2007;356(4):335-47.

24. Schauwvlieghe A, Buil JB, Verweij PE, Hoek RAS, Cornelissen JJ, Blijlevens NMA, et al. High-dose posaconazole for azole-resistant aspergillosis and other difficult-to-treat mould infections. Mycoses. 2020;63(2):122-30.

25. Shen Y, Huang XJ, Wang JX, Jin J, Hu JD, Yu K, et al. Posaconazole vs. fluconazole as invasive 
fungal infection prophylaxis in China: a multicenter, randomized, open-label study. Int J Clin Pharmacol Ther. 2013;51(9):738-45.
26. Cornely OA, Maertens J, Winston DJ, Perfect J, Ullmann AJ, Walsh TJ, et al. Posaconazole vs. fluconazole or itraconazole prophylaxis in patients with neutropenia. N Engl J Med. 2007;356(4): 348-59. 